\title{
An investigation of back-propagation neural network on university selection
}

\begin{abstract}
Processing thousands of applications can be a challenging task, especially when the applicant does not consider the university requirements and their qualification, while in some cases, the selection officer may face difficulties in deciding if more than one candidate has the same qualification for a limited vacancy of a particular program. In this paper, we present an investigation on university selection using back-propagation neural network to assist the selection officer in selecting eligible applicants based on SPM results. The experiments have shown the back-propagation method produced better performance with the average more than $90 \%$ accuracy for student selection across all of sets of the test data.
\end{abstract}

Keyword: Applicant; Back-propagation; Selection; Student; University; University requirements 